\title{
The Acceptance of the i-NILAM System by Librarian Media Teacher
}

\author{
*Nor Azah Mansor, Nor Hasbiah Ubaidullah, Ramlah Mailok \\ Universiti Pendidikan Sultan Idris, Malaysia \\ *azahmsr@gmail.com
}

\begin{abstract}
The i-NILAM system is a system that records activity of Nadi Ilmu Amalan Membaca (NILAM) in school. In order to predict user acceptance in technology, the researchers have decided to assess the current system based on theory acceptance model. The Technology Acceptance Model has been adopted as the theoretical framework to determine whether it could help to explain actual individual behavior using the technology. A questionnaire survey has been used and it involves 120 librarian media teachers from schools in Batang Padang district. More importantly, this system will contribute to the efficiency of the management of NILAM Programme. This paper also discusses the theory acceptance model which is a specific model based to explain and expect consumer acceptance towards technology. The results of structural equation modeling using AMOS 18 supported the adequacy of research model.
\end{abstract}

Keywords: NILAM Program, i-NILAM system, TAM, Information Technology acceptance, Construct Validity

\section{Introduction}

Nowadays, teachers are facing with multiple tasks such as conducting co-curriculum activities and taking over clerical and administrative job. Therefore, Information and Communication Technology (ICT) is a device or computer data processing which comes to help teachers to make the right decisions, effective and inclusive without reference to the principals, teachers and senior teachers. The i-NILAM system has been introduced in 2007 by Bios One Sdn. Bhd. "Program NILAM" is a consolidation of all motivational reading activity in school by giving suitable recognition. Usually, students write a summary of book and teachers will validate and evaluate it manually. The initial research showed that existing process of recording book was time-consuming, decentralize and prone to making errors. With i-NILAM System, calculation and analysis will automatically generate a better process. Teachers are insufficient knowledge and skills, especially in Information and Communication Technology (ICT) (Baek, Jung, \& Kim, 2008). A survey from Becker (1999), states about three activities that particular teachers usually do that is finding information and other resources on the Internet; e-mailing with teachers at other schools; and posting information, suggestions, opinions, or student work on the World Wide Web. The objective of this study is: (1) to identify the perceived usefulness and ease of use of representative of i-NILAM System. (2). is it perceived ease of use influenced perceived usefulness and attitude towards using the system. (3) To determine whether perceived usefulness influence attitudes towards using and behavioral intention to use. (4) To clarify is it attitude towards using is one of the factors influences to behavioral intention. This paper focuses on the initial stage in the design and development process in order to identify the correct model and implement appropriate counter measures.

\section{Literature Review}

Technology acceptance model (TAM) is an information system theory that models how to accept and use a computer-based technology. Theory Acceptance Model (TAM) is an extensive theory of reasoned action (TRA) proposed by Fishbein and Ajzen that explained the relationship between user belief, attitudes, intentions, and actual system use. TRA begins with intention, attitudes toward the behavior and subjective norms users in forming beliefs. TRA included subjective norm (SN) as a variable which influences by peers and superiors. It suggests that perceived usefulness (PU) and perceived ease of use (PEOU) are the two main belief variables for computer acceptance behavior (Davis, Bagozzi \& Warshaw, 1989). Figure 1 shows the original Technology Acceptance Model. Specifically in this context, perceived usefulness is defined as the degree to which a librarian media teacher believes that using i-NILAM system would enhance his or her job performance whereas perceived ease of use is defined as the degree to which a librarian media teacher expected computer technology to be free of mental effort. In this model, attitude toward using is a central feature that is affected by perceived usefulness and ease of use (Saeed, Yang \& Sinnappan, 2008). Behavioral intention is measuring the strength of a desire to produce specific behaviors towards the use of information systems (Maslin \& Ramlah, 2008). Most studies in psychology 
and information systems have shown that behavioral intention is a strong predictor of actual usage behavior (Sun \& Zhang, 2006).

Figure 1 : Original Technology Acceptance Model

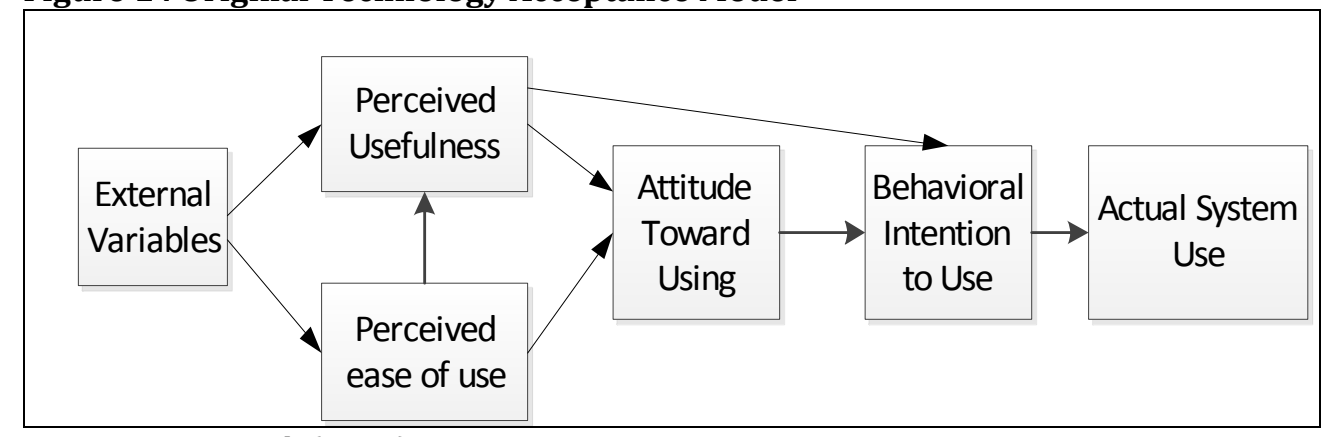

Source: Davis et al. (1989)

Research Model and Hyphothesis: Figure 2 depicts the research model developed in the study. This model is excluding actual behavior. Teachers are being likely to perceive a technology as easy to use and accept the new technology when they are capability using the technology (Chang, Lieu, Liang, Liu \& Wong, 2012). This concept includes the use of goal clarity and ease of use of information systems for the purpose of the system according to the wearer's desire. Teacher's belief that i-NILAM System gives them benefits and will increase their interest to use the technology (Davis et al., 1989). Findings from Hu and Bentler (1998) stated that perceived usefulness had a significant effect towards attitude and intention but perceived ease of use was not. Therefore, we propose the following hypothesis to test the objectives of the research.

H1: Perceived ease of use (PEOU) has a significant effect on perceived usefulness (PU) of the system.

$\mathrm{H} 2$ : Perceived ease of use (PEOU) has a significant effect on attitude towards using.

H3: Perceived usefulness (PU) has a significant effect on attitude towards using.

H4: Perceived usefulness (PU) positively influences intention to use the i-NILAM system.

H5: Attitude towards using has a significant effect on behavioral intention to use.

\section{Figure 2: Research Model}

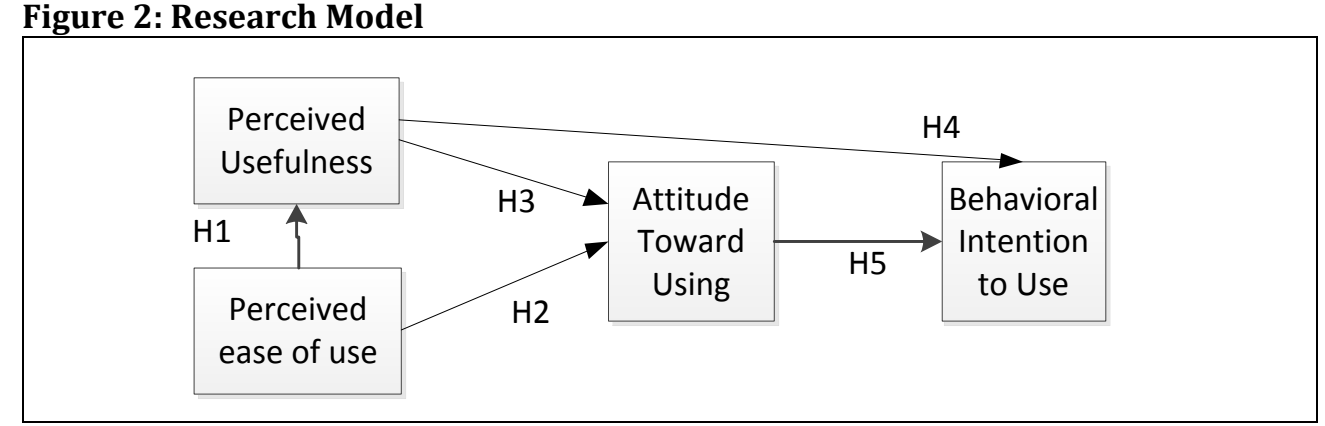

\section{Methodology}

The population of the research was the librarian media teachers in Batang Padang district school. The sample size of this questionnaire is 88 according to 5 people per items estimated using SEM analysis (Bentler \& Chou, 1987). The questionnaire was designed based on theory on Technology Acceptance Model. The experiment was conducted via online within a month. Then, the participants were asked to fill out a demographic survey which collected information regarding their age, gender, experience in teaching and handling NILAM Program. After completing the demographic survey, subjects completed the four construct using Likert scale. These constructs had been modified according to previous research (Chuttur, 2009; Davis et al., 1989; Hu et al., 1999; Wu \& Wang, 2005). The entire experiment did not exceed one hour. The average duration was 15 minutes.

\section{Data analysis and result}

The average of respondents' age is between 30 to 39 years and their average of experience in handling NILAM program is more than 3 years. Out of 120 librarian teachers in Batang Padang, 88 were answered 
via online. Data analysis was conducted using SPSS and AMOS statistical application. As shown in Table 1, the value of Cronbach's alpha was above 0.70, indicating the degree of homogeneity of items in an instrument or scale. Next, we examined the good-fit of the full-fledged research model (Figure 3). There are 6 steps validity in finding evidence of good questionnaire. First are face validity, content validity, predictive validity, concurrent validity, convergent validity and discriminant validity. The researcher chooses face validity and convergent validity. Convergent validity is selected because every loading is close to or above 0.70 . The result of the average variance extracted (AVE) is all over 0.5. AVE for PU= 0.75 , PEOU $=0.59, \mathrm{ATT}=0.78$, ITU $=064$ by using this formula;

$\mathrm{AVE}=$ (sum of squared standardized loading) / (sum of squared standardized loading + sum of indicator measurement error)

Specifically, six goodness-of-fit were used, including chi-square, goodness-of-fit index (GFI), adjusted goodness-of-fit index (AGFI), normalized fit index (NFI), comparative fit index (CFI), root mean square error of approximation (RMSEA) (Schreiber, Nora, Stage, Barlow \& King, 2006). Table 2 summarizes the values observed in the field together with an acceptable level of common model fit indexes. As indicated, all indicators are passed the acceptable level; they were close enough to indicate that the model fit was reasonably adequate. There is one strong correlation between task fast and save time. It shows teachers spend less time when using i-NILAM system.

The data also supported most of the individual causal paths postulated by TAM. Perceived usefulness had a significant being 0.89 and 0.47 , respectively. Literally, these coefficients direct positive effect on a librarian media teacher's attitude as well as on his or her intention to use the technology. These coefficients suggested that every unit increment in perceived usefulness would strengthen an individual's positive attitude by 0.89 units and at the same time increase his or her intention to use i-NILAM System with 0.47 units. Effects of attitude on intention were also significant and showed a 0.59 path coefficient. It means every unit attitude goes up; intention to use will goes up by 0.59 standard deviations. Otherwise perceived ease of use had negative effects on both attitude and perceived usefulness. It shows when perceived ease of use goes up by 1 standard deviation, perceived usefulness goes down by 0.46 standard deviations. Result of perceived ease of use towards attitude is -0.03 that is when PEOU goes up by 1 standard deviation, ATT goes down by 0.03 standard deviations. Therefore, $\mathrm{H} 2$ was rejected; where $\mathrm{H} 1$, H3, H4 and H5 was fail to reject (Table 3)

Table 1: Cronbach's alpha (Reliability)

\begin{tabular}{ll}
\hline Scale & Cronbach's alpha \\
\hline Perceived usefulness (PU) & 0.957 \\
Perceived ease of use (PEOU) & 0.863 \\
Attitude (ATT) & 0.876 \\
Intention to use (ITU) & 0.766 \\
\hline
\end{tabular}

Table 2: Analysis of Overall Model Goodness-of-Fit Using Common Fit Indexes

\begin{tabular}{|c|c|c|}
\hline goodness-of-fit- & Acceptable level & $\begin{array}{l}\text { Results obtained from the } \\
\text { study (Revised Model) }\end{array}$ \\
\hline Probability & $>0.05$ & 0.171 \\
\hline Goodness-of-fit index (GFI) & 0 (no fit) to 1 (perfect fit) & 0.916 \\
\hline $\begin{array}{l}\text { Adjusted goodness-of-fit index } \\
\text { (AGFI) }\end{array}$ & 0 (no fit) to 1 (perfect fit) & 0.854 \\
\hline Normalized fit index (NFI) & 0 (no fit) to 1 (perfect fit) & 0.946 \\
\hline Comparative fit index (CFI) & 0 (no fit) to 1 (perfect fit) & 0.990 \\
\hline $\begin{array}{l}\text { Root mean square error of } \\
\text { approximation (RMSEA) }\end{array}$ & $<0.05$ & 0.050 \\
\hline
\end{tabular}

Discussion : Based on data collected, the fairly reasonable GFI and significant model path suggest the general applicability of TAM to teacher use of i-NILAM system. The results for PEOU toward PU is significant with $r=-0.45$. The correlation between PEOU towards PU was occurring even though weak; it is not merely a coincidence. The correlation between PEOU towards ATT is inherently small. Generally the result for PU has supported the hypothesis. The pattern discovered was that when librarian media teachers understand the usefulness of computer utilization, they are more likely to use the tool. The data 
indicated that perceived usefulness was relatively more influential than perceived ease of use in affecting the use of computer technology. Therefore, we contend that usefulness has both direct and indirect (through attitude toward using) significant impact on the intention to use. Findings did not support of TAM by Davis et al. (1989), perceived ease of use supposes influenced attitude. As hypothesized based on TAM, perceived ease of use was found to affect attitude to a lesser extent than perceived usefulness. Djamasbi, Fruhling and Loiacono (2009), shows result only a significant path between usefulness and attitude but not between ease of use and attitude. Similar to a prior study examining the acceptance of a healthcare information system by physicians did not find a significant relationship between the system's ease of use and the users' attitude ( $\mathrm{Hu}$ et al., 1999). This suggests the relative importance of the perceived usefulness of the technology. Perceived usefulness also had a significant direct impact on the intention to use. This study suggests that the developer should stresses on the ease of use for i-NILAM System. Perceived ease of use may increase as teacher becomes used to the i-NILAM system and have more experienced with the technology. This relationship remains to be investigated with added new observe variables.

\section{Figure 3: Research Model}

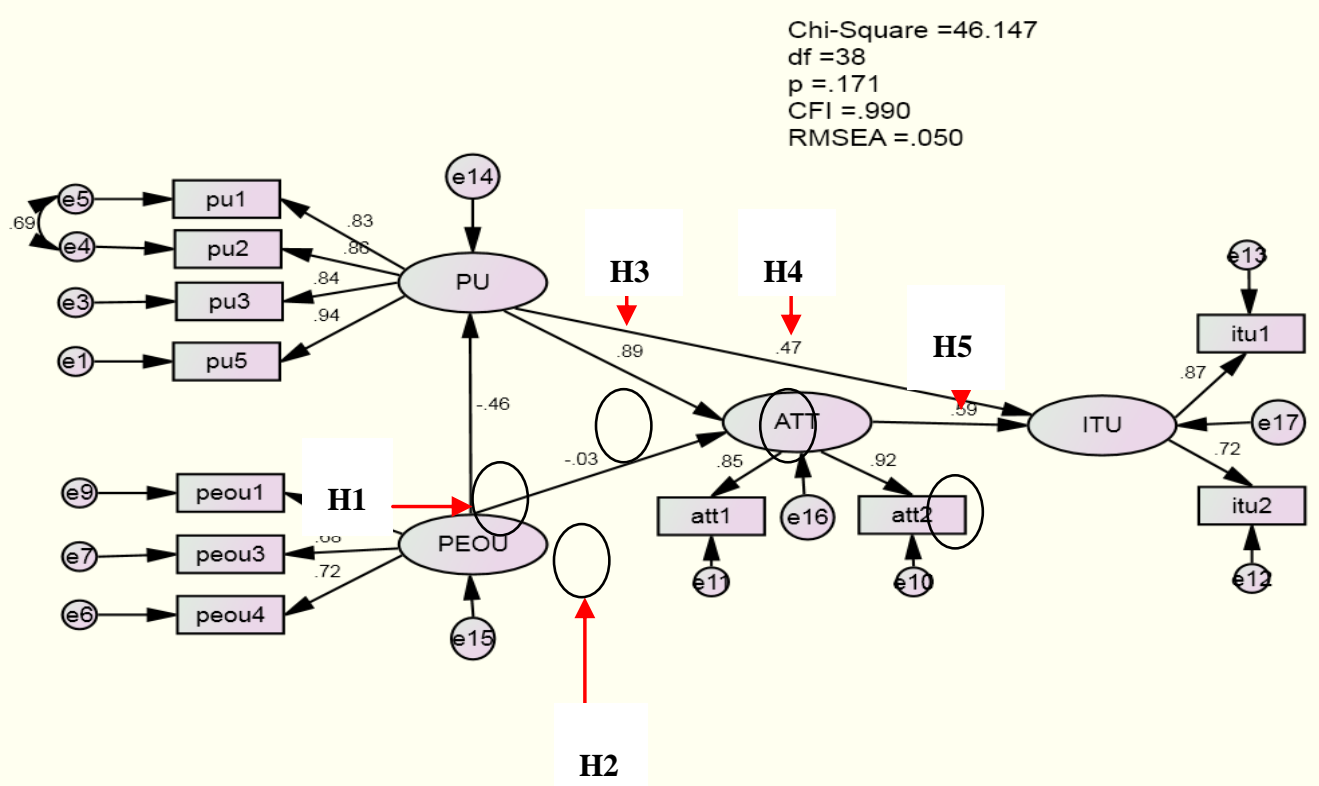

Table 3: Summary of Hypotheses

\begin{tabular}{lll}
\hline Hypotheses & Result & Result \\
\hline $\begin{array}{l}\text { H1: Perceived ease of use (PEOU) has a significant effect on } \\
\text { perceived usefulness (PU) of the system. }\end{array}$ & Significant & Supported \\
$\begin{array}{l}\text { H2: Perceived ease of use (PEOU) has a significant effect on } \\
\text { attitude towards using. }\end{array}$ & Not Significant & Not Supported \\
$\begin{array}{l}\text { H3: Perceived usefulness (PU) has a significant effect on } \\
\text { attitude towards using. }\end{array}$ & Significant & Supported \\
$\begin{array}{l}\text { H4: Perceived usefulness (PU) positively influences intention } \\
\text { to use the i-NILAM system. }\end{array}$ & Positive & Supported \\
$\begin{array}{l}\text { H5: Attitude towards using has a significant effect on } \\
\text { behavioral intention to use. }\end{array}$ & Singnificant & Supported \\
\hline
\end{tabular}

\section{References}

Baek, Y., Jung, J. \& Kim, B. (2008). What makes teachers use technology in the classroom? Exploring the factors affecting facilitation of technology with a Korean sample. Computers \& Education, 50(1), 224-234. 
Becker, H. J. (1999). Internet use by teachers: Conditions of professional use and teacher-directed student use (Vol. 1). Center for Research on Information Technology and Organizations, the University of California, Irvine and the University of Minnesota.

Bentler, P. M. \& Chou, C. P. (1987). Practical issues in structural modeling. Sociological Methods \& Research, 16(1), 78-117.

Chang, J. L., Lieu, P. T., Liang, J. H., Liu, H. T. \& Wong, S. L. (2012). A causal model of teacher acceptance of technology. Educational Research and Reviews, 7(5), 102-110.

Chuttur, M. (2009). Overview of the technology acceptance model: Origins, developments and future directions. Retrieved from http://sprouts.aisnet.org/9-37/

Davis, F. D., Bagozzi, R. P. \& Warshaw, P. R. (1989). User acceptance of computer technology: a comparison of two theoretical models. Management Science, 35(8), 982-1003.

Djamasbi, S., Fruhling, A. L. \& Loiacono, E. (2009). The influence of affect, attitude and usefulness in the acceptance of telemedicine systems. Journal of Information Technology Theory and Application (JITTA), 10(1).

Hu, L. \& Bentler, P. M. (1998). Fit Indices in Covariance Structure Modeling: Sensitivity to Underparameterized Model Misspecification. Psychological methods, 3(4), 424-453.

Hu, P. J., Chau, P. Y., Sheng, O. R. L. \& Tam, K. Y. (1999). Examining the technology acceptance model using physician acceptance of telemedicine technology. Journal of management information systems, 16(2), 91-112.

Maslin, M. \& Ramlah, H., (2008). User Acceptance of Information Technology: Understanding Theories and Models. Selangor: Venton Publishing (M) Sdn. Bhd.

Saeed, N., Yang, Y. \& Sinnappan, S. (2008). Media richness and user acceptance of Second Life. In Proc. of Ascilite.

Schreiber, J. B., Nora, A., Stage, F. K., Barlow, E. A. \& King, J. (2006). Reporting Structural Equation Modeling and Confirmatory Factor Analysis Results: A Review. The Journal of Educational Research, 99(6), 323-338.

Sun, H. \& Zhang, P. (2006). The role of moderating factors in user technology acceptance. International Journal of Human-Computer Studies, 64(2), 53-78.

Wu, J. H. \& Wang, S. C. (2005). What drives mobile commerce?: An empirical evaluation of the revised technology acceptance model. Information \& management, 42(5), 719-729. 